\section{Iron-Catalyzed Epoxidations with Hydrogen Peroxide}

Metal-Catalyzed Asymmetric Synthesis and Stereoselective

Reactions

\section{Key words}

\section{iron}

asymmetric epoxidation

hydrogen peroxide

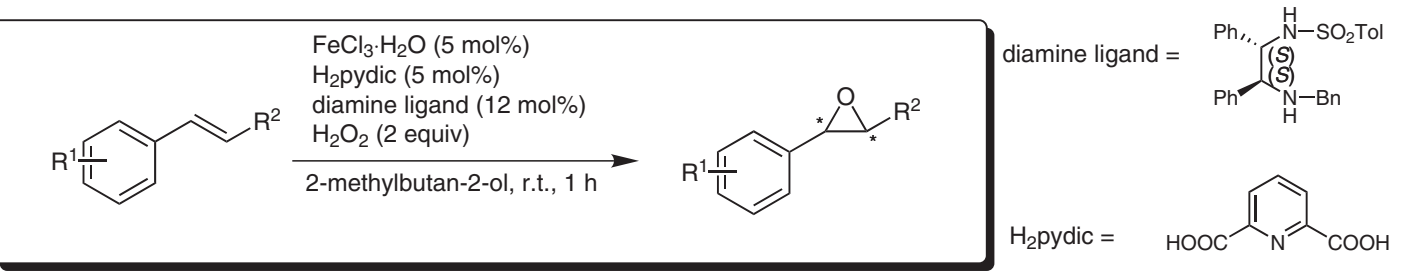

Selected examples:

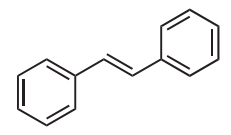<smiles>C/C=C/c1ccccc1</smiles><smiles>CC(C)(C)c1cccc(/C=C/c2cccc(C(C)(C)C)c2)c1</smiles>

$87 \%$ yield, $42 \%$ ee $94 \%$ yield, $28 \%$ ee<smiles>Cc1ccccc1/C=C/c1ccccc1C</smiles>

$57 \%$ yield, $55 \%$ ee

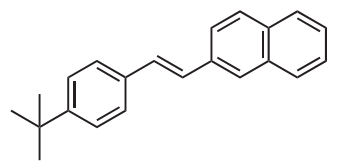

$46 \%$ yield, $91 \%$ ee
Significance: Asymmetric epoxidations give enantioenriched oxiranes which are versatile intermediates in fine chemical synthesis. Currently, most methods involve either atom-inefficient oxidants or the use of expensive transition metals. The authors report an iron catalyst/hydrogen peroxide based method to access chiral oxiranes in high yields and moderate to high enantioselectivities.

Review: Previous work with Ru: M. Beller and coworkers Chem. Eur. J. 2006, 12, 1855.
Comment: To date, the combination of iron catalysts and hydrogen peroxide gave only moderate results in epoxidation reactions. Using the new method, chiral oxiranes can be obtained in high yields and enantioselectivities vary with steric bulk in the substrate. Small ortho substituents still give good results (only one example). Increasing steric bulk in the meta-position diminishes the selectivity and unsymmetrically substituted alkenes can be converted in moderate enantioselectivities. The stereochemistry of the products was proven by derivatization to known compounds. 